\title{
An Enquiry into Teachers' and Students' Perceptions on the Role of Grade 12 English Textbook in Enhancing the Strategic Competence Abilities of Students: The Case of Wolaita Sodo Secondary and Preparatory School
}

\author{
Tesfaye Buche Bosha \\ College of Social Sciences and Humanities Department of English Language and Literature, Wolaita Sodo \\ University, Sodo Ethiopia
}

\begin{abstract}
The purpose of this study was an enquiry into teachers' and students' perceptions on the role of grade 12 English textbook in enhancing the strategic competence abilities of students: The case of Wolaita Sodo Secondary and Preparatory School. Descriptive Survey research design was employed for the current study. To collect the necessary data for the study, semi-structured interview for two teachers, questionnaire for sixty-five students and document analysis were employed. To analyze the collected data, qualitative and quantitative methods of data analysis were employed. That is, data collected through questionnaire were analyzed employing statistical tools such as frequency and percentage using SPSS version 20, while responses obtained from interview were described and discussed. In addition, the data obtained from document analysis which were presented in tables and explained qualitatively to validate and triangulate the data obtained from interview and questionnaire. From the analysis of data, different findings were obtained. The study depicted that different communicative contents and activities that cultivate strategic competence abilities of students presented in Grade 12 English Textbook. The data collected from students via questionnaire show that most students were not interested in the communicative contents and activities that can enhance different communicative abilities of students. The data collected from teachers via semi-structured interview show that some of the communicative contents and activities that enhance students' different communicative abilities need to be revised and organized in the way that help students. The result of content analysis also substantiated that some contents and activities need to be revised. Based on the findings, conclusions were drawn and recommendations were forwarded to improve the perceptions of teachers and students as well as to revise some contents of the textbook.
\end{abstract}

Keywords: Perceptions, Textbook, Strategic Competence and communicative Contents

DOI: $10.7176 /$ JLLL/73-01

Publication date: November $30^{\text {th }} 2020$

\section{Introduction}

Grant (1990: 13) claims that communicative textbooks create possibilities for students to communicate in the language because they consist of many communicative activities. As a result, students will be able to use the language when they have finished school. According to Canale and Swain (1980:25) strategic competence is 'how to cope in an authentic communicative situation and how to keep the communicative channel open'. Strategic competence consists of using of using communication strategies. These strategies come into play when learners are unable to express what they want to say because they lack the resources to do so successfully. They compensate for this either by changing their original intension or by searching for other means of expression. The significant implications of strategic competence for teaching and learning are to be able to take risks in using both spoken and written language, to use range of communication strategies and to learn the language needed to engage in some of these strategies.

Richards (2010) perception is (in teaching) the effective aspects of the classroom, such as the feelings generated by and about the teacher, the students or the subject matter, along with aspects of the classroom itself that contribute positively or negatively to the learning atmosphere. Perception is the awareness of something through the senses. In other words, it is the ability to see, hear, understand or become aware of something. Perception is how you see the world and relate to everything around you. It is how you understand and internalize everything you experience. Perception means the state of being or process of becoming aware of something through the senses. It has a great role in teaching and learning language.

Behind this perception, there is consciousness. Five senses play the role in the perception process. Perception is the use of the mind or the senses to comprehend or understanding a person's surroundings and it determines the person's actual feeling about something or someone, which is called attitude. "Perception is defined as something that is being observed and what is and what is said about it" Campbell (1967). Therefore, current study was intended to investigate teachers and students' Perceptions on the Role of Grade 12 English Textbook in Enhancing the Strategic Competence abilities of Students: The Case of Wolaita Sodo Secondary and Preparatory School. 


\section{Statement of the Problem}

There are also designed English teaching learning materials for Ethiopian students for each grade level such as syllabus, Teacher's Guide and students' Textbook. After all, from my experience of teaching English for ten years, students who completed grade 12 and have been learning in grade 12 fail to perform communicative functions using English Language. As a result, I am initiated to conduct a study to answer what was the problem behind, to analyze whether the textbook was organized and designed according to the aims and objectives of syllabus, or not, to explore whether communicative contents and communicative activities were represented in the Textbook, or not. Because it was as discussed under the background of this study, Textbook plays great role in cultivating the communicative abilities of students.

Furthermore, in using textbooks properly, both teachers' and students' perception play great role. It may encourage or discourage the implementation of textbook in English classroom and it may delay or promote using textbook to improve communicative abilities.

The review of local studies revealed that some studies were conducted on this area. For example, Abebe Tilahun (2016) conducted a study on English Textbook in Ethiopia from Teachers' and Students' Perspectives: The Case of Grade 12 Students' Textbook at Addis Ketema Secondary and Preparatory School in Awassa. The researcher used survey research design and Random and available sampling techniques for students and teachers respectively. Besides, questionnaire and interview were used to gather necessary data. Finally, findings of the study revealed that textbook satisfies teachers' and students' regarding on its layout and physical appearance, the Textbook satisfies in question objectives, activities and tasks, in language input, skills, structure and vocabulary.

\section{Research Design and Methodology}

\subsection{Design of the Study}

In order to achieve the intended objectives of the study, descriptive survey research design was employed. According to Kothari (2004) descriptive research studies are those studies which are concerned with describing the characteristics of a particular individual or of group. Since the current study was an exploration into teachers' and students' perceptions on the role of grade 12 English textbook in enhancing strategic competence, descriptive survey design was appropriate to describe the perceptions of both teachers and students. Regarding to research method, the researcher employed both qualitative and quantitative methods. Quantitative method was used to collect data from students via questionnaire; whereas, qualitative method was used to collect data from teachers via semi structured interview.

\subsection{Research Setting}

The study was conducted in Wolaita Sodo Preparatory School, particularly in grade 12 English students textbook, which was located in Southern Nations Nationalities and People Regional State in Wolaita Zone in Sodo City.

\subsection{Participants of the Study}

Sampling is important when the population of the study is large and difficult to manage it due to different reasons. But here, in the selected school the number of population was sixty-five. This number was manageable regardless of time, cost and human resource. With respect to this, Kothari (2004) states that a complete numeration of the items in the population is known as a census inquiry. It can be presumed that in such an inquiry when all the items are covered no element of chance left and highest accuracy is obtained. Accordingly, all 65 were taken as the participants of the study. In addition, there were two English language teachers in the selected preparatory school. Thus, both of them were included in the study because it was believed that they can provide the data needed for this study. Both grade 12 students and teachers were selected intentionally; because when grade 12 students join university, they were expected to read a lot of courses in English as well as they made a lot of presentations in English so that they should have communicative abilities. Accordingly, it was believed that the students can have adequate information about the textbook. Besides, they were mature enough than other grades in high school level, so they could make balanced judgement about the textbook.

\subsection{Data Collection Instruments}

Three data collection instruments were used to gather the necessary data for this study. These are questionnaire, semi-structured interview and document analysis.

\subsection{Data collection procedures}

In this study, data were collected via questionnaire, semi-structured interview and document analysis. As it is mentioned earlier, the subject of the study was all Wolaita Sodo grade 12 students and their English teachers due to relevant and adequate data for the purpose of this study. The researcher assisted students during the completion of questions so that he couldn't administer interview at the same time. Therefore, the researcher administered data gathering tools at different time. First, data from students via questionnaire were collected. 
Next, the researcher administered interview to two English teachers of Wolaita Sodo preparatory school. Finally, data from grade 12 English textbook were collected.

\subsection{Method of Data Analysis}

Data that were collected via the above tools, were analyzed by using various methods. In this study, the quantitative data which were collected from the respondents through open ended and close ended questions of the questionnaire were analyzed quantitatively and statically described using frequency and percentage. Regarding to the data that were gathered using interview, first the researcher transcribed recorded data, then the researcher selected data relevant to the objectives of the study through reading the general idea. Next, the selected data were categorized thematically to answer the research questions in meaningful way. Furthermore, the data from textbook were collected, were summarized using frequency and percentage. Then, the proportion and percentage of communicative contents and communicative activities were compared and contrasted with the other contents and activities included in the textbook. The results of comparison and contrasts were summarized using numbers and percentage. Then, the results were described qualitatively using sentences and expressions.

The results obtained via the above tools were integrated during data presentation, analysis and interpretation. Integrating the results helped the researcher to validate the findings obtained from one tool by the other tool. It also helped to substantiate and support the findings via different tools. In this study, the integration was made as follows: first, the results obtained via questionnaire and interview were presented. Second, the result from the two were compared to see the validity of findings obtained from the questionnaire by the interview. Thirdly, the results of document analysis were presented and analyzed. Forth, the results of document analysis were used to validate the responses obtained via questionnaire and interview. Fifth, the findings from questionnaire and interview were substantiated and supported by the results of document analysis. Finally, based on the presentation, analysis and interpretation of the data, the researcher summarized the research findings, drew meaningful conclusions and suggested recommendations.

\subsection{Pilot Study}

Pilot test is important to check clarity and relevance of the questions to achieve the purpose of the study. In this study, both questionnaire and interview were pilot tested. As a result, before data collection process takes place for the main study, the adopted and modified questionnaire were administered to 20 students of Sodo preparatory school to check clarity and relevance of the questionnaire items as well as interview questions were also administered to two English teachers of Otona preparatory school who could give creative comments. Based on the pilot result of the pilot study, necessary improvements were made on the questionnaire items and interview questions. Finally, after improving the questions, the tools were used to gather data for the main study.

\section{Results and Discussions}

Table 1: Students' perception on the role of communicative contents and activities in Grade 12 English Textbook that enhance students' strategic abilities.

\begin{tabular}{|c|c|c|c|c|c|c|c|c|c|c|c|c|c|}
\hline \multirow[t]{3}{*}{ No } & \multirow[t]{3}{*}{ Items } & \multicolumn{12}{|c|}{ Responses } \\
\hline & & \multicolumn{2}{|c|}{$\begin{array}{l}\text { strongly } \\
\text { disagree }\end{array}$} & \multicolumn{2}{|c|}{ disagree } & \multicolumn{2}{|c|}{ undecided } & \multicolumn{2}{|c|}{ agree } & \multicolumn{2}{|c|}{$\begin{array}{c}\text { strongly } \\
\text { agree }\end{array}$} & \multicolumn{2}{|c|}{ Total } \\
\hline & & $\mathbf{F}$ & $\%$ & $\mathbf{F}$ & $\%$ & $\mathbf{F}$ & $\%$ & $\mathbf{F}$ & $\%$ & $\mathbf{F}$ & $\%$ & $\mathbf{F}$ & $\%$ \\
\hline 1 & $\begin{array}{l}\text { I believe the communicative } \\
\text { activities in the Textbook help } \\
\text { students to take risks in using } \\
\text { spoken language. }\end{array}$ & 12 & 18.5 & 31 & 47.7 & 8 & 12.3 & 11 & 16.9 & 3 & 4.6 & 65 & 100 \\
\hline 2 & $\begin{array}{l}\text { I think the communicative } \\
\text { activities in the Textbook help } \\
\text { students to use range of } \\
\text { communication strategies. }\end{array}$ & 14 & 21.5 & 22 & 33.8 & 9 & 13.8 & 16 & 24.6 & 4 & 6.2 & 65 & 100 \\
\hline
\end{tabular}

As it can be seen from Table 1 , most of the respondents, $66.2 \%$ thought that the communicative contents and activities in the textbook cannot help students to take risk in using spoken language. $21.5 \%$ of the respondents thought that the communicative contents and activities in the textbook help students to take risk in using spoken language. The remaining, $12.3 \%$ respondents have no idea about the communicative contents and activities in the textbook that enhance strategic abilities of students. This indicates that students perceive communicative contents and activities that enhance strategic abilities of students differently based on their feelings.

In respect to item number 1 , as it can be seen from Table 19, most of the respondents, $55.3 \%$ thought that the communicative contents and activities in the textbook cannot enhance students to use range of communication strategies. $30.8 \%$ of the respondents thought that communicative contents and activities in the 
textbook help students to use range of communication strategies. The remaining, $13.8 \%$ respondents have no idea about the communicative contents and activities in the textbook that help students to use range of communication strategies. This indicates that students perceived communicative contents and activities that enhance strategic abilities of students differently based on their feelings.

In conclusion, most of the respondents have negative feelings about the communicative contents and activities in the textbook that enhance strategic abilities of students. Some students have positive feelings towards the communicative contents and activities in the textbook that enhance strategic abilities of students. Besides, a few students have no idea about the communicative contents and activities in the textbook that enhance the strategic abilities of students.

Furthermore, regarding to the communicative objectives in Grade 12 English Textbook, two English Teachers were asked about the communicative objectives in the textbook and answered as follows: Both T1 and T2 asked about the communicative contents and activities that enhance students' strategic abilities and answered that it is difficult to believe communicative contents and activities that enhance communicative contents and activities presented in the textbook.

Table 2: The Results of Content Analysis on Communicative Contents and Activities that Enhance Strategic Abilities of Students

\begin{tabular}{|l|l|l|l|l|l|l|l|l|l|l|l|l|l|}
\hline No. & Types of abilities & U1 & U2 & U3 & U4 & U5 & U6 & U7 & U8 & U9 & U10 & U11 & U12 \\
\hline 1 & $\begin{array}{l}\text { Taking risks in using spoken } \\
\text { language }\end{array}$ & & & & & & & & & & & \\
\hline 2 & $\begin{array}{l}\text { Using range of communicative } \\
\text { strategies }\end{array}$ & $\checkmark$ & $\checkmark$ & & & & & & & & & \\
\hline
\end{tabular}

Strategic abilities are essential for students, especially for EFL students, because strategic abilities refer to 'how to cope in an authentic communicative situation and how to keep the communicative channel open'. Strategic ability consists of using communication strategies. These strategies come into play when learners are unable to express what they want to say because they lack the resources to do so successfully. They compensate for this either by changing their original intension or by searching for other means of expression. As it is seen above in table 6 , contents and activities of strategic abilities only presented in two units. This was not fair presentation and I think, the Textbook developers didn't consider the big role of strategic competence for EFL students. For example, one of the content is provided below:

\title{
B Fillers
}

\section{Look at these expressions:}

$\begin{array}{llll}\text { Er ... } & \text { Wait a moment ... } & \text { Let me think ... } & \text { You know, ... } \\ \text { Ummm ... } & \text { May I think about that for a moment? } & \text { Hang on .... } \\ \text { You see ... } & \text { Oh, I don't know ... } & \text { How shall I put it? ... } & \text { What's it called? } \\ \text { Well umm ... } & \text { Well actually ... } & \text { Ah yes, now ... } & \text { Well as far as I can see ... }\end{array}$

These expressions are called fillers. They are called this because we use them to fill the spaces when we are thinking about what to say or the words to use.

\author{
Example: Student A: What's the capital of India? \\ Student B: Er... Let me think. Umm... It's umm... Mumbai, no it isn't! Umm. It's ... \\ What's it called? I know... it's Delhi! Yes, Delhi!
}

\section{Summary, Conclusions and Recommendations \\ 5.1 Summary of Major Findings}

Most of the English teachers believe that almost of functional and strategic competence communicative contents and activities could enhance oral communication of students, but most of students and teachers had negative feelings towards functional and strategic competence communicative contents and activities. Most of respondents were not interested in the communicative contents and activities that cultivate linguistic strategic abilities of students.

\subsection{Conclusions}

The study depicted that different communicative contents and activities that cultivate strategic competence abilities of students presented in Grade 12 English Textbook. The data collected from students via questionnaire show that most students were not interested in the communicative contents and activities that can enhance different communicative abilities of students. The data collected from teachers via semi-structured interview show that some of the communicative contents and activities that enhance students' different communicative 
abilities need to be revised and organized in the way that help students. The result of content analysis also substantiated that some contents and activities need to be revised.

\subsection{Recommendations}

Some of the communicative contents and activities that enhance linguistic, socio-linguistic, discourse and strategic abilities of students should be revised in the way that cultivate students' communicative abilities and should be supported by authentic examples. Therefore, Ministry of Education of Ethiopia should reconsider issues related with communicative contents that cultivate strategic competence and EFL teachers should adapt materials accordingly.

\section{References}

Abebe Tilahun (2016). English textbook in Ethiopia from teachers' and students' perspectives. International journal on studies in English language and literature. Vol 4, issue 8 PP

Canale, M., \& M. Swain (1980). Theoretical Bases of Communicative Approaches to Second Language Teaching and Testing. Applied linguistics 1/1. PP

FDRE, MoE (2003 E.C). English for Ethiopian Grade 12 students Text book: England, Pearson Education Ltd.

Grant (1990). Textbooks and Alternative Materials. Journal of Education. Vol 172, NO 2 PP

Grant, N. (1987). Making the most of your textbook, New York Longman Inc.

Richards, J.C. \& Schmidt, R. (2010) Longman dictionary of language teaching and applied linguistics. Harlow, UK: Longman.

Richards, J.C (1994). Reflective teaching in the language classroom Cambridge: CUP.

Richards, J.C (2001). Curriculum development in language teaching New York: Cambridge University Press.

Richards, J.C (2001). The role of textbook in a language program. Cambridge: Cambridge University Press.

Richards, J.C (2006). Communicative language teaching today Cambridge: Cambridge University Press.

Roger Seguin (1989). The Elaboration of Language Textbook, Contents and Methods of Education. UNESCO.

Rogers, E. (2003). The Diffusion of Innovations (5th Ed.). New York: Free Press.

Tilahun Tulu (2010). An Exploration of English for Ethiopian Grade 12 students' textbook in cultivating students' paragraph writing skills (unpublished M.A thesis).Jimma University. 